\title{
Severe pneumococcal pneumonia: impact of new quinolones on prognosis
}

\author{
David Olive ${ }^{1}$, Hugues Georges ${ }^{1}$, Patrick Devos ${ }^{2}$, Nicolas Boussekey ${ }^{3}$, Arnaud Chiche $^{3}$, Agnes Meybeck ${ }^{3}$, \\ Serge Alfandari ${ }^{3}$, Olivier Leroy ${ }^{3 *}$
}

\begin{abstract}
Background: Most guidelines have been proposing, for more than 15 years, a $\beta$-lactam combined with either a quinolone or a macrolide as empirical, first-line therapy of severe community acquired pneumonia (CAP) requiring ICU admission. Our goal was to evaluate the outcome of patients with severe CAP, focusing on the impact of new rather than old fluoroquinolones combined with $\beta$-lactam in the empirical antimicrobial treatments.

Methods: Retrospective study of consecutive patients admitted in a 16-bed general intensive care unit (ICU), between January 1996 and January 2009, for severe (Pneumonia Severity Index > or $=4$ ) community-acquired pneumonia due to non penicillin-resistant Streptococcus pneumoniae and treated with a $\beta$-lactam combined with a fluoroquinolone.

Results: We included 70 patients of whom 38 received a $\beta$-lactam combined with ofloxacin or ciprofloxacin and 32 combined with levofloxacin. Twenty six patients (37.1\%) died in the ICU. Three independent factors associated with decreased survival in ICU were identified: septic shock on ICU admission (AOR $=10.6 ; 95 \% \mathrm{Cl} 2.87-39.3 ; \mathrm{p}=$ 0.0004), age $>70 \mathrm{yrs}$. ( $\mathrm{AOR}=4.88 ; 95 \% \mathrm{Cl} 1.41-16.9 ; \mathrm{p}=0.01)$ and initial treatment with a $\beta$-lactam combined with ofloxacin or ciprofloxacin (AOR $=4.1 ; 95 \% \mathrm{Cl} 1.13-15.13 ; \mathrm{p}=0.03)$.

Conclusion: Our results suggest that, when combined to a $\beta$-lactam, levofloxacin is associated with lower mortality than ofloxacin or ciprofloxacin in severe pneumococcal community-acquired pneumonia.
\end{abstract}

\section{Background}

Streptococcus pneumoniae is the leading causative agent of community-acquired pneumonia (CAP). Despite new antimicrobial agents and advances in supportive measures, attributable mortality linked to pneumococcal pneumonia remains unchanged and dramatically high when patient are admitted in intensive care units (ICU) [1].

Most guidelines have been proposing, for more than 15 years, a combination of a $\beta$-lactam with either a quinolone or a macrolide as empirical, first-line therapy of severe CAP requiring ICU admission [2-8]. Although a recent study demonstrated combination antibiotic therapy to be associated with a higher survival rate than monotherapy in patients with severe CAP and shock [9], the rationale for this combination was not to increase efficacy but rather to routinely provide coverage of all

\footnotetext{
* Correspondence: oleroy@ch-tourcoing.fr

${ }^{3}$ Service de Réanimation Médicale et Maladies Infectieuses. Hôpital Chatiliez. Tourcoing 59 - France

Full list of author information is available at the end of the article
}

common pathogens causing severe CAP and particularly, S. pneumoniae and Legionella species.

In our ICU, we followed until 2003 the 1991 French recommendations [2]. Most patients received an empirical therapy based on a $\beta$-lactam-fluoroquinolone combination. Before 2003, fluoroquinolones used were ofloxacin and ciprofloxacin. Levofloxacin replaced these quinolones since its 2003 addition to the hospital formulary. Such a replacement was comforted by the ERS, French and IDSA guidelines published between 2005 and 2007 [6-8]. We wished to determine outcomes of patients treated with a combination of $\beta$-lactam plus fluoroquinolone for severe pneumococcal pneumonia. This homogenous modification of severe CAP antibiotic management in our ICU gives us the further opportunity to assess the influence of a fluoroquinolone with enhanced activity against S.pneumoniae.

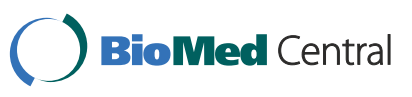

() 2011 Olive et al; licensee BioMed Central Ltd. This is an Open Access article distributed under the terms of the Creative Commons Attribution License (http://creativecommons.org/licenses/by/2.0), which permits unrestricted use, distribution, and reproduction in any medium, provided the original work is properly cited. 


\section{Methods Patients}

Firstly, we retrospectively collected all consecutive patients aged $>18$ years who were admitted into our ICU (16-bed medical and surgical intensive care unit in a 450-bed general hospital) between January 1996 and January 2009 for severe community-acquired pneumonia (CAP) and who received a definite diagnosis of pneumococcal pneumonia. Secondly, we selected patients who received, as initial antibiotic treatment, a $\beta$-lactam plus a fluoroquinolone, used with an appropriate dosage by IV route. Thirdly, patients were divided into two groups according to the fluoroquinolone used, Group A for ofloxacin or ciprofloxacin, Group B for levofloxacin. The study protocol was submitted to the Institutional Review Board for University Hospital of Lille which gave an approval with waiver of informed consent, in agreement with French regulations concerning such retrospective studies.

CAP was defined by the following criteria observed at initial presentation or occurring within $48 \mathrm{~h}$ following hospitalization: acute onset of signs and symptoms of lower respiratory tract infection and a new pulmonary infiltrate found on the hospital admission chest radiograph. We excluded patients coming from nursing homes or hospitalized within 90 days prior to developing pneumonia or hospitalized $>48 \mathrm{~h}$ in general medical wards before ICU admission, and those with radiographic abnormalities attributed solely to any other known cause (i.e., pulmonary embolus, lung carcinoma or congestive heart failure). The decision for admission to our ICU was made, in all cases, by the attending physicians. However, only patients having a Pneumonia Severity Index (PSI) score $\geq 4$ were included in this study [10].

Streptococcus pneumoniae was considered as the causative agent of CAP when a S. pneumoniae strain was isolated from $>1$ blood culture or when validated sputum $(<10$ squamous epithelial cells and $>25$ polymorphonuclear cells per low-power field) or tracheobronchial aspirates cultures grew with $>10^{5} \mathrm{cfu} / \mathrm{mL}$ S. pneumoniae. Patients having CAP due to a penicillinresistant strain of $S$. pneumoniae (MIC $>2 \mathrm{mg} / \mathrm{l}$ ) were excluded from our study.

Appropriate drug dosages were defined in the French recommendations as: amoxicillin $>50 \mathrm{mg} / \mathrm{kg} / \mathrm{d}$, cefotaxime $>50 \mathrm{mg} / \mathrm{kg} / \mathrm{d}$, ceftriaxone $>20 \mathrm{mg} / \mathrm{kg} / \mathrm{d}$, piperacillin $>200 \mathrm{mg} / \mathrm{kg} / \mathrm{d}$, ofloxacin $=200 \mathrm{mg} / 12 \mathrm{~h}$, ciprofloxacin $=$ $400 \mathrm{mg} / 12 \mathrm{~h}$, levofloxacin $=500 \mathrm{mg} / 12 \mathrm{~h}[2,3,7]$. These drug dosages for $\beta$-lactams, ofloxacin and ciprofloxacin were unchanged during the study period. Thus, doses used in both groups were similar.

\section{Data collection, evaluation and definition}

Within $24 \mathrm{~h}$ of admission, all patients underwent clinical, radiological and biological tests. Briefly, we recorded age, gender, underlying clinical characteristics and initial vital signs. Chronic respiratory insufficiency was assessed combining the usual clinical and radiological criteria and the coexistence of ventilatory impairment assessed either before or after ICU stay. Immunosuppression was defined as recent use of immunosuppressant or systemic corticosteroids (i.e., prednisolone $>0.5 \mathrm{mg} / \mathrm{kg} /$ day for more than 1 month), human immunodeficiency virus infection, neutropenia (absolute neutrophil count $<1.000$ cells $/ \mathrm{mm} 3$ ), organ transplantation with ongoing immunosuppressant, cancer chemotherapy within the past 3 months, or asplenia. Shock was defined as a sustained $(>1 \mathrm{~h})$ decrease in the systolic blood pressure of at least $40 \mathrm{~mm} \mathrm{Hg}$ from baseline or a resultant systolic blood pressure $<90 \mathrm{~mm} \mathrm{Hg}$ after adequate volume replacement and in the absence of any antihypertensive drug [11]. Severity of illness at admission to ICU was assessed using the Simplified Acute Physiology Score II (SAPS) II [12], the Sepsis-related Organ Failure Assessment (SOFA) score [13] and the logistic organ dysfunction (LOD) score [14]. We also calculated the PSI at ICU admission [10]. For all patients, information on the following therapeutic topics instituted within 48 hours following ICU admission was recorded: supportive measures such as mechanical ventilation or hemodialysis, use of vasopressor drugs, hydrocortisone, drotrecogin alfa (activated), or intensive insulin therapy. The effectiveness of initial antimicrobial therapy was assessed within $72 \mathrm{~h}$ after treatment as follows: A lack of clinical improvement 3 days after treatment initiation (worsening or persistent fever or hypothermia, worsening of pulmonary infiltrates or of respiratory function assessed by $\mathrm{PaO}_{2} / \mathrm{FiO}_{2}$ ) defined an ineffective treatment. On day 3, day 5 and day 7, body temperature, and SOFA score were determined. During the patient's stay in the ICU, occurrence of complications was recorded. We distinguished sepsis-related complications (secondary septic shock, acute respiratory distress syndrome or development of multiple organ failure), hospital-acquired lower respiratory tract (HA-LRT) superinfections and ICU-related complications (i.e., upper gastrointestinal bleeding, catheter-related infection, deep venous thrombosis and pulmonary embolism). Multiple organ failure (MOF), acute respiratory distress syndrome (ARDS) and HA-LRT were defined according to usual criteria [15-17]. Durations of mechanical ventilation, treatment with vasopressor drugs, and ICU length of stay were noted. 
Finally, patient mortality was evaluated on D-15, and at the time of ICU discharge.

\section{Methods of analysis}

Descriptive analyses were performed in order to check and resume data. Characteristics of patients in each group were compared. Continuous variables were compared using the Student's t test. Categorical variables were compared using Chi-square test or Fisher's exact test when Chi-square was not appropriate. Differences between groups were considered to be significant for variables yielding a $\mathrm{p}$ value $<0.05$. A stepwise logistic regression including variables collected within the first 48 hours of ICU stay and associated with a $p$ value $<0.15$ in bivariate analysis was performed. Adjusted odd-ratios were computed using a logistic regression analysis including the independent predictors of mortality. The Kaplan-Meier product limit method and the log-rank test were used to construct and compare survival curves for patients in each group.

All statistical analyses were performed using the SAS Software, V9.1.

\section{Results}

During the study period, 378 patients with severe CAP were admitted in our unit. Among them, 83 (22\%) patients exhibited a severe pneumococcal pneumonia and, finally, we identified 70 patients treated with a $\beta$-lactam combined with a fluoroquinolone, including 53 men $(75.7 \%)$ and 17 women $(24.3 \%)$. The mean age was $63.8 \pm 16.8$ years.
S. pneumoniae was identified in blood cultures in 25 patients (35.7\%). Infection was polymicrobial in 18 patients (25.7\%). Causative pathogens associated with S. pneumoniae were Haemophilus influenzae $(\mathrm{n}=7)$, methicillin susceptible Staphylococcus aureus $(\mathrm{n}=4)$, enterobacteriaceae ( $\mathrm{n}=4)$, Streptococcus spp. $(\mathrm{n}=2)$ and Moraxella catarrhalis $(\mathrm{n}=2)$. All pathogens were susceptible to at least one drug ( $\beta$-lactam and/or fluoroquinolone) received by the patients. Thirty-eight patients $(54.3 \%)$ were classified as Group A. $\beta$-lactams used were a third generation cephalosporin $(\mathrm{n}=20 ; 52.6 \%)$, amoxicillin \pm clavulanic acid $(\mathrm{n}=16 ; 42.1 \%)$ and piperacillin-tazobactam $(\mathrm{n}=2$; $5.3 \%)$ combined with ofloxacin $(\mathrm{n}=33$; $86.8 \%)$ or ciprofloxacin $(\mathrm{n}=5 ; 13.2 \%)$. Thirty-two patients $(45.7 \%)$ were classified as Group B. $\beta$-lactams used were a third generation cephalosporin $(\mathrm{n}=26$; $81.3 \%)$, amoxicillin \pm clavulanic acid $(\mathrm{n}=5 ; 15.6 \%)$ and piperacillin-tazobactam $(\mathrm{n}=1$; $3.1 \%)$ combined with levofloxacin.

Main patients' characteristics on ICU admission are reported Table 1. Most characteristics were similar in the two groups. However, underlying chronic respiratory insufficiency and bacteremia were more frequent in Group B patients.

Main therapeutics instituted during ICU stay, evolution of severity scores, and occurrence of complications are reported Table 2. The most significant differences between the two groups of patients were the more frequent use of drotrecogin alpha, intensive insulin therapy and hydrocortisone in Group B patients.

On Day 15, $14(20 \%)$ patients had died, $12(31.6 \%)$ in Group A and $2(6.3 \%)$ in Group B ( $=0.02)$.

Table 1 Characteristics of patients with severe pneumococcal pneumonia on ICU admission*

\begin{tabular}{|c|c|c|c|c|}
\hline Characteristics & Overall population $n=70$ & Group A $n=38$ & Group B $n=32$ & $p$ \\
\hline Age (years) & $63.8 \pm 16.8$ & $63.5 \pm 16.5$ & $64.1 \pm 17.4$ & 0.87 \\
\hline Male & $53(75.7 \%)$ & $30(78.9 \%)$ & $23(71.9 \%)$ & 0.49 \\
\hline Female & $17(24.3 \%)$ & $8(21.1 \%)$ & $9(28.1 \%)$ & \\
\hline Malignancy & $5(7.1 \%)$ & $3(7.9 \%)$ & $2(6.3 \%)$ & 0.70 \\
\hline Diabetes mellitus & $11(15.7 \%)$ & $4(10.5 \%)$ & $7(21.8 \%)$ & 0.19 \\
\hline Chronic heart failure & $11(15.7 \%)$ & $5(13.1 \%)$ & $6(18.7 \%)$ & 0.52 \\
\hline Chronic respiratory insufficiency & $12(17.1 \%)$ & $3(7.9 \%)$ & $9(28.1 \%)$ & 0.02 \\
\hline Immunosuppression & $13(18.5 \%)$ & $9(23.6 \%)$ & $4(12.5 \%)$ & 0.23 \\
\hline SAPS $\|$ & $52.9 \pm 19.5$ & $53.3 \pm 20.3$ & $52.5 \pm 18.9$ & 0.86 \\
\hline LOD score & $7.3 \pm 4.0$ & $7.6 \pm 4.0$ & $6.8 \pm 4.0$ & 0.40 \\
\hline SOFA score & $8.3 \pm 3.9$ & $9.0 \pm 4.1$ & $7.5 \pm 3.5$ & 0.10 \\
\hline PSI 4 & $21(30 \%)$ & $14(36.8 \%)$ & $7(21.9 \%)$ & 0.17 \\
\hline PSI 5 & $49(70 \%)$ & $24(63.2 \%)$ & $25(78.1 \%)$ & \\
\hline Temperature $\left({ }^{\circ} \mathrm{C}\right)$ & $37.9 \pm 1.5$ & $38.2 \pm 1.4$ & $37.5 \pm 1.5$ & 0.04 \\
\hline ARF requiring MV & 55 (78.5\%) & $30(78.9 \%)$ & $25(78.1 \%)$ & 0.93 \\
\hline Septic shock & $34(48.5 \%)$ & $17(44.7 \%)$ & $17(53.1 \%)$ & 0.48 \\
\hline Bacteremia & $25(35.7 \%)$ & $9(23.6 \%)$ & $16(50 \%)$ & 0.02 \\
\hline
\end{tabular}

*Data are presented as No. (\%) or mean \pm SD.

MV: mechanical ventilation; SAPS: simplified acute physiology score; LOD score: logistic organ dysfunction score: SOFA: Sepsis-related Organ Failure Assessment score; PSI: Pneumonia Severity Index; ARF: Acute Respiratory Failure. 
Table 2 Therapeutics data and evolution during ICU stay of patients with severe pneumococcal pneumonia*

\begin{tabular}{|c|c|c|c|c|}
\hline Characteristics & Overall population $n=70$ & Group A $n=38$ & Group B $n=32$ & $P$ \\
\hline Cephalosporin in initial treatment & $46(65.7 \%)$ & $20(52.6 \%)$ & $26(81.3 \%)$ & 0.01 \\
\hline Use of drotrecogin alpha & $4(5.7 \%)$ & 0 & $4(12.5 \%)$ & 0.02 \\
\hline Intensive insulin therapy & $30(42.8 \%)$ & $4(10.5 \%)$ & $26(81.2 \%)$ & $<0.0001$ \\
\hline Use of hydrocortisone & $24(34.3 \%)$ & $6(15.7 \%)$ & $18(56.3 \%)$ & 0.0004 \\
\hline Haemodialysis & $10(14.3 \%)$ & $3(7.8 \%)$ & $7(21.8 \%)$ & 0.09 \\
\hline Body temperature on D3 & $37.4 \pm 1.3$ & $37.8 \pm 1.0$ & $36.9 \pm 1.3$ & 0.0008 \\
\hline SOFA score on D3 & $7.5 \pm 4.8$ & $8.0 \pm 5.1$ & $7.1 \pm 4.5$ & 0.48 \\
\hline Improvement on D3 & $43(61.4 \%)$ & $20(52.6 \%)$ & $23(71.8 \%)$ & 0.09 \\
\hline Body temperature on D5 & $37.5 \pm 0.9$ & $37.7 \pm 0.9$ & $37.3 \pm 0.9$ & 0.22 \\
\hline SOFA score on D5 & $6.4 \pm 4.8$ & $7.5 \pm 4.9$ & $5.5 \pm 4.5$ & 0.13 \\
\hline Body temperature on D7 & $37.4 \pm 1.0$ & $37.7 \pm 0.9$ & $37.0 \pm 1.0$ & 0.04 \\
\hline SOFA score on D7 & $6.6 \pm 5.0$ & $7.7 \pm 5.0$ & $5.6 \pm 4.8$ & 0.17 \\
\hline Sepsis-related complications & $31(44.3 \%)$ & $16(42.1 \%)$ & $15(46.8 \%)$ & 0.68 \\
\hline HA-LRT superinfections & $17(24.3 \%)$ & $7(18.4 \%)$ & $10(31.2 \%)$ & 0.21 \\
\hline ICU-related complications & $12(17.1 \%)$ & $8(21.0 \%)$ & $4(12.5 \%)$ & 0.34 \\
\hline Duration of MV (days) & $11.3 \pm 14.3$ & $11.2 \pm 15.6$ & $11.5 \pm 12.9$ & 0.93 \\
\hline Duration of vasopressor use (days) & $3.5 \pm 4.8$ & $3.6 \pm 5.6$ & $3.3 \pm 3.9$ & 0.80 \\
\hline LOS in ICU (days) & $14.6 \pm 16.3$ & $14.5 \pm 19.0$ & $14.6 \pm 12.6$ & 0.97 \\
\hline Mortality on D-15 & $14(20 \%)$ & $12(31.6 \%)$ & $2(6.3 \%)$ & 0.02 \\
\hline Mortality in ICU & $26(37.1 \%)$ & $17(44.8 \%)$ & $9(28.1 \%)$ & 0.15 \\
\hline
\end{tabular}

*Data are presented as No. (\%) or mean \pm SD.

MV: mechanical ventilation; SAPS: simplified acute physiology score; LOD score: logistic organ dysfunction score: SOFA: Sepsis-related Organ Failure Assessment score; PSI: Pneumonia Severity Index; HA-LRT superinfections: hospital-acquired lower respiratory tract superinfections; LOS = length of stay.

Overall, 26 patients died in the ICU, 17 (44.8\%) in group A vs. $9(28.1 \%)$ in group B $(\mathrm{p}=0.15)$. So, difference in mortality rates was only significant during the first 15 days of ICU stay (Figure 1). In Group A, in-ICU mortality was $45 \%$ (9/20) when ofloxacin or ciprofloxacin were combined with a third generation cephalosporin and $44.4 \%(8 / 18)$ when combined with another beta-lactam, respectively $(\mathrm{p}=0.97)$. In group $\mathrm{B}$, it was $26.9 \%(7 / 26)$ when levofloxacin was combined with a third generation cephalosporin and $33.3 \%(2 / 6)$ when combined with another beta-lactam $(\mathrm{p}=1)$.

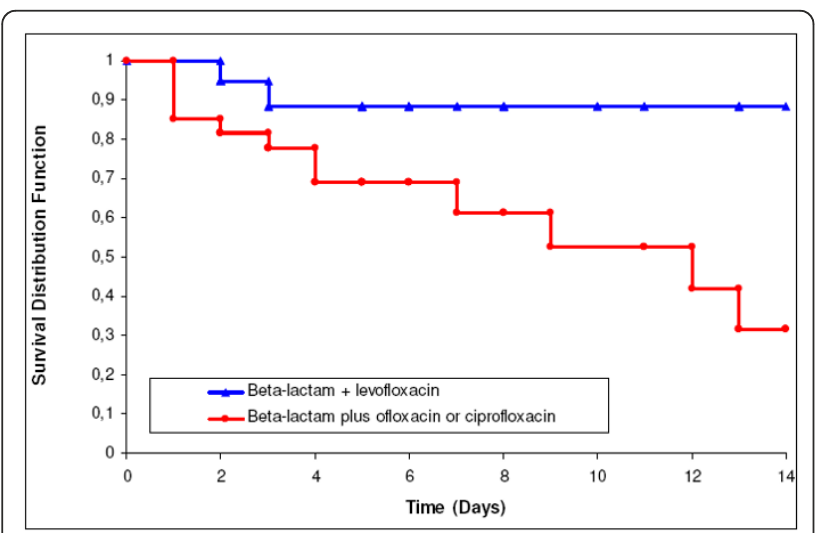

Figure 1 15-day survival curves in patients treated with $\beta$ lactam combined with levofloxacin versus $\beta$-lactam combined with ofloxacin or ciprofloxacin. Log rank test: $p=0.031$.
Results of ICU-discharge survival prognosis bivariate analysis, including factors present on ICU admission, are reported Table 3. All underlying diseases (excepted chronic heart failure), mechanical ventilation, use of a third generation cephalosporin combined with a fluoroquinolone, and bacteraemia on ICU admission did not appear as significant prognostic variables in this analysis. Among the 25 bacteremic patients, mortality was higher in group A patients $(66.6 \%)$ than group B patients $(31.3 \%)$, but the difference was not statistically significant $(6 / 9$ vs. $5 / 16 ; p=0.11)$. Among the 34 patients with septic shock on ICU admission, mortality was higher in group A patients (71\%) than in Group B patients $(47 \%)$, but the difference was not statistically significant $(8 / 17$ vs. $12 / 17 ; \mathrm{p}=0.30)$.

Among variables collected during the ICU stay, use of hydrocortisone, intensive insulin therapy, haemodialysis and occurrence of HA-LRT superinfections did not appear as significant prognostic variables. Conversely, improvement on D3, SOFA $>8$ on D3, D5, and D7, and occurrence of sepsis-related complications were significantly associated with outcome at ICU discharge (Table 4).

According to the results of the bivariate analysis, the following variables were entered in the stepwise analysis: chronic heart failure, age $>70 \mathrm{yrs}$, acute respiratory failure requiring mechanical ventilation, septic shock on ICU admission, use of hydrocortisone, haemodialysis, PSI score $=5$, SAPS II $>50$ on D1, LOD $>8$ on D1, 
Table 3 Bivariate analysis of variables collected on D1 influencing the outcome, at ICU discharge, of pneumococcal CAP*

\begin{tabular}{llll}
\hline Variables & Survivors $\mathbf{n}=\mathbf{4 4}$ & Non survivors $\mathbf{n}=\mathbf{2 6}$ & $\mathbf{p}$ \\
\hline Age $>$ 70 yrs. & $14(31.8 \%)$ & $16(61.6 \%)$ & 0.01 \\
Gender: Male/Female & $33 / 11$ & $20 / 6$ & 0.85 \\
Malignancy & $4(9.0 \%)$ & $1(3.8 \%)$ & 0.41 \\
Diabetes mellitus & $7(15.5 \%)$ & $4(15.4 \%)$ & 0.95 \\
Chronic heart failure & $4(9.1 \%)$ & $7(26.9 \%)$ & 0.04 \\
Chronic respiratory insufficiency & $8(18.2 \%)$ & $4(15.4 \%)$ & 0.76 \\
Immunosuppression & $10(22.7 \%)$ & $3(11.5 \%)$ & 0.24 \\
SAPS II >50 & $18(40.1 \%)$ & $19(73.1 \%)$ & 0.009 \\
LOD $>8$ & $13(29.5 \%)$ & $16(61.6 \%)$ & 0.008 \\
SOFA >8 & $14(31.8 \%)$ & $18(69.3 \%)$ & 0.002 \\
PSI $4 / 5$ & $17 / 27$ & $4 / 22$ & 0.04 \\
MV on D1 & $32(72.7 \%)$ & $23(88.4 \%)$ & 0.12 \\
Septic shock & $14(31.8 \%)$ & $20(76.9 \%)$ & 0.0003 \\
Bacteremia & $14(31.8 \%)$ & $11(42.3 \%)$ & 0.37 \\
Patients in Group A/Group B & $21 / 23$ & $17 / 9$ & 0.15 \\
Cephalosporin in initial treatment & $30(68.2 \%)$ & $16(61.6 \%)$ & 0.57 \\
\hline
\end{tabular}

*Data are presented as No. (\%).

MV: mechanical ventilation; SAPS: simplified acute physiology score; LOD score: logistic organ dysfunction score: SOFA: Sepsis-related Organ Failure Assessment score; PSI: Pneumonia Severity Index.

SOFA $>8$ on D1 and initial treatment with a $\beta$-lactam combined with ofloxacin or ciprofloxacin (Group A).

Three independent factors associated with outcome at ICU discharge were identified: septic shock on ICU admission $(\mathrm{AOR}=10.6 ; 95 \% \mathrm{CI} 2.87-39.3 ; \mathrm{p}=0.0004)$, age $>70$ yrs. $(\mathrm{AOR}=4.88 ; 95 \% \mathrm{CI} 1.41-16.9 ; \mathrm{p}=0.01)$ and initial treatment with a $\beta$-lactam combined with ofloxacin or ciprofloxacin $(\mathrm{AOR}=4.1 ; 95 \% \mathrm{CI} 1.13-15.13 ; \mathrm{p}=0.03)$.

\section{Discussion}

The main finding of this retrospective analysis is that levofloxacin plus a $\beta$-lactam appears to be associated with improved survival compared to ofloxacin or ciprofloxacin plus a $\beta$-lactam in severe pneumococcal CAP.

\begin{tabular}{|c|c|c|c|}
\hline Variables & $\begin{array}{l}\text { Survivors } \\
n=44\end{array}$ & $\begin{array}{l}\text { Non survivors } \\
\mathrm{n}=26\end{array}$ & $p$ \\
\hline Use of hydrocortisone & $12(27.3 \%)$ & $12(46.2 \%)$ & 0.1 \\
\hline Intensive insulin therapy & $18(40.9 \%)$ & $12(46.2 \%)$ & 0.66 \\
\hline Haemodialysis & $6(13.6 \%)$ & $4(15.4 \%)$ & 0.1 \\
\hline Improvement on D3 & $36(81.8 \%)$ & 7 (26.9\%) & $<0.0001$ \\
\hline SOFA $>8$ on D3 & $9(20.5 \%)$ & $14(53.8 \%)$ & $<0.0001$ \\
\hline SOFA $>8$ on D5 & $10(22.7 \%)$ & $14(53.8 \%)$ & 0.0001 \\
\hline SOFA $>8$ on D7 & $10(22.7 \%)$ & $13(50 \%)$ & 0.009 \\
\hline Sepsis-related complications & $14(31.8 \%)$ & 17 (65.4\%) & 0.006 \\
\hline HA-LRT superinfections & $8(18.2 \%)$ & $9(34.6 \%)$ & 0.12 \\
\hline
\end{tabular}

*Data are presented as No. (\%).

SOFA: Sepsis-related Organ Failure Assessment score; HA-LRT superinfections: hospital-acquired lower respiratory tract superinfections.
Empirical antibiotic regimen for ICU-treated severe CAP has long been recommended to cover the 3 most common severe CAP pathogens (S. pneumoniae, S. aureus and H.influenzae), atypical pathogens and most relevant Enterobacteriaceae species. Levofloxacin is a fluoroquinolone active against most of these pathogens, especially S. pneumoniae with or without decreased penicillin susceptibility $[18,19]$. Its clinical activity in CAP has been well documented in various clinical trials in Europe and the USA $[20,21]$. Some studies demonstrated the efficacy of levofloxacin used as monotherapy in severe CAP, compared to ceftriaxone plus erythromycin or cefotaxime plus ofloxacin [22,23]. Nevertheless, experts continue to propose, for ICU-treated severe CAP, an empirical antibiotic regimen based on an anti pneumococcal $\beta$-lactam combined with either a macrolide or a fluoroquinolone. Since respiratory fluoroquinolones with enhanced activity against S. pneumoniae (levofloxacin, moxifloxacin or gemifloxacin) became available, they replaced second generation fluoroquinolones (ofloxacin or ciprofloxacin) in the guidelines [6-8]. This fluoroquinolone generation shift has never been clearly justified and, to our knowledge, no clinical study has compared these different quinolones combined with a $\beta$-lactam in severe CAP. Our results suggest that, when severe CAP causative agent is S. pneumoniae, a combination levofloxacin plus $\beta$-lactam is associated with lower mortality than a combination ofloxacin or ciprofloxacin plus $\beta$-lactam.

These results could be surprising as all patients received an appropriately dosed $\beta$-lactam active against S. pneumoniae and as numerous strains of S. pneumoniae 
remain in vitro susceptible to ofloxacin or ciprofloxacin. However, there might be bacteriological and clinical data explaining our results. A synergy between $\beta$-lactams and levofloxacin against $S$. pneumoniae has been reported [24]. Conversely, synergy was rarely observed between the combination of cefotaxime and ofloxacin [25]. Recent clinical studies suggest that combination therapies could improve the prognosis of pneumococcal pneumonia: Waterer et al. retrospectively studying 225 patients with severe bacteremic pneumococcal pneumonia demonstrated that a single effective therapy was an independent predictor of mortality $(\mathrm{AOR}=6.2)$ [26]. Baddour et al. performed a prospective, multicenter, international study including 844 adult patients with $S$. pneumoniae bacteremia [27]. Although the 14-day mortality was not significantly different for all patients receiving monotherapy versus combination (11.5\% vs. $10.4 \%)$, a combination of in vitro active agents was associated with a significantly lower mortality than a single active agent $(19.4 \%$ vs. $60 \%$; $\mathrm{p}=0.0006)$.

The present work has numerous limits. The most important is probably major treatment differences among the two groups. Patients were recruited during a long period (1996-2009), during which therapies such as hydrocortisone, drotrecogin alfa (activated), or intensive insulin therapy were introduced. Management of septic shock and ARDS has changed following results of large international studies [28,29]. As most changes in management of patients with multiple organ failures overlap with our antibiotic policy changes, our results might be biased. Indeed, hydrocortisone use and intensive insulin therapy were more frequent in group B than in Group A. However, these factors were not significantly associated with ICU survival in bivariate analysis and hydrocortisone use, in multivariate analysis, was not an independent prognostic factor. Moreover, there is no evidence suggesting a survival benefit by most adjunctive therapies in patients with CAP [30] and the benefit of intensive insulin therapy in medical ICU and/or low-dose steroids is now highly questionable [31,32]. Similarly, the use of cephalosporin is more frequent in group $B$ than in group A. However, the use of a third generation cephalosporin rather than amoxicillin has no impact on prognosis. This is not surprising as, to our knowledge, no clinical study demonstrated a third generation cephalosporin to be superior to amoxicillin for non penicillin-resistant S. pneumoniae CAP as far as drug dosage is adequate. Finally, some important prognostic parameters such as the time elapsed between admission and the first dose of antibiotic were not taken into account in our study. Before 2006, we did not have computerized data charts thus, exact time of admission and antibiotics admission, particularly for patients transferred from other departments/hospitals cannot be obtained.

\section{Conclusions}

Our study suggests that levofloxacin combined with a $\beta$-lactam is associated with improved survival in comparison with ofloxacin or ciprofloxacin combined with a $\beta$-lactam in severe pneumococcal patients admitted in the ICU. This combination, proposed by current guidelines as empirical treatment of severe CAP patients admitted in ICU could improve their prognosis. Obviously, only a prospective, randomized, double-blind trial could confirm this result.

\section{List of abbreviations}

AOR: adjusted odd ratio; ARDS: acute respiratory distress syndrome; CAP: community-acquired pneumonia; Cl: confidence interval; HA-LRT superinfections: hospital-acquired lower respiratory tract superinfections; ICU: intensive care unit; LOD score: logistic organ dysfunction score; LOS: length of stay; MOF: multiple organ failure; MV: mechanical ventilation; PSI: pneumonia severity index; SAPS: simplified acute physiology score; SOFA: sepsis-related organ failure assessment; SD: standard deviation.

\section{Acknowledgements}

The writers thank G. Moran for collaboration in the writing of this paper.

\section{Author details}

${ }^{1}$ Service de Réanimation Médicale et Maladies Infectieuses. Hôpital Chatiliez. Tourcoing 59 - France. ${ }^{2}$ Département de bio statistiques. CHRU Lille. 59 France. ${ }^{3}$ Service de Réanimation Médicale et Maladies Infectieuses. Hôpital Chatiliez. Tourcoing 59 - France.

\section{Authors' contributions}

DO collected data and helped to draft the manuscript., HG participated in the design of the study, collected data and helped to draft the manuscript, PD performed the statistical analysis., NB collected data and helped to draft the manuscript, AC collected data and helped to draft the manuscript, AM collected data and helped to draft the manuscript, SA collected data and helped to draft the manuscript, and OL contributed to the design of the study and wrote the manuscript. All authors read and approved the final manuscript.

\section{Competing interests}

The authors declare that they have no competing interests.

Received: 12 July 2010 Accepted: 15 March 2011

Published: 15 March 2011

\section{References}

1. Georges H, Leroy O, Vandenbussche C, Guery B, Alfandari S, Tronchon L, Beaucaire $\mathrm{G}$ : Epidemiological features and prognosis of severe community-acquired pneumococcal pneumonia. Intensive Care Med 1999, 25:198-206.

2. Quatrième conférence de consensus en thérapeutique anti-infectieuse de la société de pathologie infectieuse de langue française: Les infections des voies respiratoires. Med Mal Inf 1991, 21(suppl Oct):1-8.

3. Huchon G, Chidiac C, Delaval P, Léophonte P, Mouton Y, Roche N, Trémolières F: Management of community-acquired lower respiratory tract infection in the adult. Recommendations by the French Language Society of Pneumology with collaboration of the French Language Society of Infectious Pathology, from the recommendations of the European Respiratory Society. Rev Mal Respir 1999, 16:224-233.

4. Bartlett JG, Dowell SF, Mandell LA, File TM Jr, Musher DM, Fine MJ: Practice guidelines for the management of community-acquired pneumonia in 
adults. Infectious Diseases Society of America. Clin Infect Dis 2000 31:347-382.

5. Niederman MS, Mandell LA, Anzueto A, Bass JB, Broughton WA, Campbell GD, Dean N, File T, Fine MJ, Gross PA, Martinez F, Marrie TJ, Plouffe JF, Ramirez J, Sarosi GA, Torres A, Wilson R, Yu VL, American Thoracic Society: Guidelines for the management of adults with community-acquired pneumonia. Diagnosis, assessment of severity, antimicrobial therapy, and prevention. Am J Respir Crit Care Med 2001, 163:1730-1754.

6. Woodhead M, Blasi F, Ewig S, Huchon G, leven M, Ortqvist A, Schaberg T, Torres A, van der Heijden G, Verheij TJ, European Respiratory Society; European Society of Clinical Microbiology and Infectious Diseases: Guidelines for the management of adult lower respiratory tract infections. Eur Respir J 2005, 26:1138-1180.

7. XVe conférence de consensus en thérapeutique anti-infectieuse: Prise en charge des infections des voies respiratoires basses de l'adulte immunocompétent. Med Mal Inf 2006, 36:235-244.

8. Mandell LA, Wunderink RG, Anzueto A, Bartlett JG, Campbell GD, Dean NC, Dowell SF, File TM Jr, Musher DM, Niederman MS, Torres A, Whitney CG: Infectious Diseases Society of America; American Thoracic Society: Infectious Diseases Society of America/American Thoracic Society consensus guidelines on the management of community-acquired pneumonia in adults. Clin Infect Dis 2007, 44(Suppl 2):S27-72.

9. Rodríguez A, Mendia A, Sirvent JM, Barcenilla F, de la Torre-Prados MV, Solé-Violán J, Rello J, CAPUCI Study Group: Combination antibiotic therapy improves survival in patients with community-acquired pneumonia and shock. Crit Care Med 2007, 35:1493-1498.

10. Fine MJ, Auble TE, Yealy DM, Hanusa BH, Weissfeld LA, Singer DE, Coley CM, Marrie TJ, Kapoor WN: A prediction rule to identify low-risk patients with communityacquired pneumonia. N Engl J Med 1997, 336:243-250

11. Levy MM, Fink MP, Marshall JC, Abraham E, Angus D, Cook D, Cohen J, Opal SM, Vincent JL, Ramsay G, International Sepsis Definitions Conference: 2001 SCCM/ESICM/ACCP/ATS/SIS International Sepsis Definitions Conference. Intensive Care Med 2003, 29:530-538.

12. Le Gall JR, Lemeshow S, Saulnier F: A new Simplified Acute Physiology Score (SAPS II) based on a European/North American multicenter study. JAMA 1993, 270:2957-2963.

13. Vincent JL, Moreno R, Takala J, Willatts S, De Mendonça A, Bruining H, Reinhart CK, Suter PM, Thijs LG: The SOFA (Sepsis-related Organ Failure Assessment) score to describe organ dysfunction/failure: on behalf of the Working Group on Sepsis-Related Problems of the European Society of Intensive Care Medicine. Intensive Care Med 1996, 22:707-710.

14. Le Gall JR, Klar J, Lemeshow S, Saulnier F, Alberti C, Artigas A, Teres D: The Logistic Organ Dysfunction system: a new way to assess organ dysfunction in the intensive care unit; ICU Scoring Group. JAMA 1996, 276:802-810.

15. Tran DD, Groeneveld AB, van der Meulen J, Nauta JJ, Strack van Schijndel RJ, Thiijs LG: Age, chronic disease, sepsis, organ system failure, and mortality in a medical intensive care unit. Crit Care Med 1990, 18:474-479.

16. Bernard GR, Artigas A, Brigham KL, Carlet J, Falke K, Hudson L, Lamy M, Legall JR, Morris A, Spragg R: The American-European consensus conference on ARDS. Am J Respir Crit Care Med 1994, 149:818-824

17. Garner JS, Jarvis WR, Emori TG, Horan TC, Hughes JM: CDC definitions for nosocomial infections. Am J Infect Control 1988, 16:128-140.

18. Davis R, Bryson HM: Levofloxacin. A review of its antibacterial activity, pharmacokinetics and therapeutic efficacy. Drugs 1994, 47:677-700.

19. Thomson KS, Chartrand SA, Sanders CC, Block SL: In-vitro activity of levofloxacin against Streptococcus pneumoniae with various levels of penicillin resistance. J Antimicrob Chemother 1999, 43(Suppl C):15-19.

20. File TM Jr, Segreti J, Dunbar L, Player R, Kohler R, Williams RR, Kojak C, Rubin A: A multicenter, randomized study comparing the efficacy and safety of intravenous and/or oral levofloxacin versus ceftriaxone and/or cefuroxime axetil in treatment of adults with community-acquired pneumonia. Antimicrob Agents Chemother 1997, 41:1965-1972.

21. Frank E, Liu J, Kinasewitz G, Moran GJ, Oross MP, Olson WH, Reichl V, Freitag S, Bahal N, Wiesinger BA, Tennenberg A, Kahn JB: A multicenter, open-label, randomized comparison of levofloxacin vs azithromycin plus ceftriaxone in hospitalized adults with moderate to severe communityacquired pneumonia. Clin Therap 2002, 8:1292-1308.

22. Fogarty C, Siami G, Kohler R, File TM, Tennenberg AM, Olson WH, Wiesinger BA, Scott Marshall JA, Oross M, Kahn JB: Multicenter, open-label, randomized study to compare the safety and efficacy of levofloxacin versus ceftriaxone sodium and erythromycin followed by clarithromycin and amoxicillin-clavulanate in the treatment of serious communityacquired pneumonia in adults. Clin Infect Dis 2004, 38:516-23.

23. Leroy $\mathrm{O}$, Saux P, Bédos JP, Caulin E, for the levofloxacin study group: Comparison of levofloxacin and cefotaxime combined with ofloxacin for ICU patients with community-acquired pneumonia who do not require vasopressors. Chest 2005, 128:172-183.

24. Kühn F, Cottagnoud M, Acosta F, Flatz L, Entenza J, Cottagnoud P: Cefotaxime acts synergistically with levofloxacin in experimental meningitis due to penicillin resistant pneumococci and prevents selection of levofloxacin-resistant mutants in vitro. Antimicrob Agents Chemother 2003, 47:2487-2491.

25. Gimeno C, Borja J, Navarro D, Valdés L, García-Barbal J, García-de-Lomas J: In vitro interaction between ofloxacin and cefotaxime against grampositive and gram negative bacteria involved in serious infections. Chemotherapy 1998, 44:94-98.

26. Waterer GW, Somes GW, Wunderink RG: Monotherapy may be suboptimal for severe bacteremic pneumococcal pneumonia. Arch Intern Med 2001, 161:1837-1842

27. Baddour LM, Yu VL, Klugman KP, Feldman C, Ortqvist A, Rello J, Morris AJ, Luna CM, Snydman DR, Ko WC, Chedid MB, Hui DS, Andremont A, Chiou CC: International Pneumococcal Study Group: Combination antibiotic therapy lowers mortality among severely ill patients with pneumococcal bacteremia. Am J Respir Crit Care Med 2004, 170:440-444.

28. The Acute Respiratory Distress Syndrome Network: Ventilation with lower tidal volumes as compared with traditional tidal volumes for Acute Lung Injury and the Acute Respiratory Distress Syndrome. N Engl J Med 2000, 342:1301-1308.

29. Dellinger RP, Levy MM, Carlet JM, Bion J, Parker MM, Jaeschke R, Reinhart K, Angus DC, Brun-Buisson C, Beale R, Calandra T, Dhainaut JF, Gerlach H, Harvey M, Marini JJ, Marshall J, Ranieri M, Ramsay G, Sevransky J, Thompson BT, Townsend S, Vender JS, Zimmerman JL, Vincent JL: Surviving Sepsis Campaign: international guidelines for management of severe sepsis and septic shock. Intensive Care Med 2008, 34:17-60.

30. Siempos II, Vardakas KZ, Kopterides P, Falagas ME: Adjunctive therapies for community-acquired pneumonia: a systematic review. I Antimicrob Chemother 2008, 62:661-668.

31. NICE-SUGAR Study Investigators, Finfer S, Chittock DR, Su SY, Blair D, Foster D, Dhingra V, Bellomo R, Cook D, Dodek P, Henderson WR, Hébert PC, Heritier S, Heyland DK, McArthur C, McDonald E, Mitchell I, Myburgh JA, Norton R, Potter J, Robinson BG, Ronco JJ: Intensive versus conventional glucose control in critically ill patients. N Engl J Med 2009, 360:1283-1287

32. Ferrer R, Artigas A, Suarez D, Palencia E, Levy MM, Arenzana A, Pérez XL, Sirvent JM, Edusepsis Study Group: Effectiveness of treatments for severe sepsis. Am J Respir Crit Care Med 2009, 180:861-866.

\section{Pre-publication history}

The pre-publication history for this paper can be accessed here: http://www.biomedcentral.com/1471-2334/11/66/prepub

doi:10.1186/1471-2334-11-66

Cite this article as: Olive et al:: Severe pneumococcal pneumonia: impact of new quinolones on prognosis. BMC Infectious Diseases 2011 11:66. 